\title{
Da força das mídias ao poder do conteúdo: revisão de modelos de negócio na publicidade ${ }^{1}$
} Cristiane Mafacioli Carvalho \& Márcia Pillon Christofoli

\section{Resumo}

Parte de pesquisa mais ampla, 0 artigo traz dados que permitem identificar que mudanças ocorrem na prática publicitária, potencializadas pelas transformações sociais, culturais e tecnológicas. Traça a evolução dos modelos de agências de publicidade no Brasil, tratando o campo publicitário e suas mudanças ao longo dos anos. A pesquisa final quer reconhecer: como essas mudanças impactam no mercado publicitário? Trata-se de uma pesquisa exploratória, com levantamento bibliográfico e documental. Como resultado, vê-se que, sem desconsiderar a lógica econômica natural do negócio publicitário, as lógicas tecnológica e simbólica começam a intervir com força no modo de pensar e fazer publicidade.

\section{Palavras-Chave}

Publicidade. Remuneração pelas mídias.

Poder do conteúdo.

\section{Cristiane Mafacioli Carvalho}

I cristiane.carvalho@pucrs.br

Doutora em Ciências da Comunicação pela Universidade do Vale do Rio dos Sinos - UNISINOS, Brasil. É professora pesquisadora do Programa de Pós-Graduação em Comunicação Social da Pontifícia Universidade Católica do Rio Grande do Sul - PUCRS, Brasil.

Márcia Pillon Christofoli I marcia.christofoli@pucrs.br Doutoranda do Programa de Pós-Graduação em Comunicação Social da Pontifícia Universidade Católica do Rio Grande do Sul - PUCRS, Brasil. É Professora do Curso de Publicidade e Propaganda da Famecos/PUCRS.

\section{Apresentação}

Como parte das preocupações de estudo do Grupo de Pesquisa Inovações das Práticas Publicitárias (INOVAPP), a pesquisa "Novos modelos e novos negócios na prática do mercado publicitário do Rio Grande do Sul"2 levantou dados e aspectos que julgou relevantes para sustentar suas questões de estudo. Dentre estas questões de pesquisa, interessa saber: (1) Que mudanças estão acontecendo nos procedimentos da prática publicitária do mercado, considerando as transformações sociais, tecnológicas e culturais da atualidade? (2) Que impactos essas mudanças trazem para o mercado da propaganda?

Por conta destas intenções de pesquisa, já circulamos por alguns campos de interesse como a revisão acerca do Tradicional e do Interativo no Fazer Publicitário e também sobre 0 Campo Publicitário, a Agência e a Noção de Aceleração do Tempo. Sobre o primeiro tema, buscamos refletir e compreender a prática publicitária neste momento de transição técnico-cultural que vivemos, em que os modelos e formatos 
são constantemente questionados. Tratamos acerca de marketing, consumo, publicidade e os aspectos de interatividade relacionados a esses tópicos. Sobre o segundo tema, traçamos aspectos referenciais que dessem conta de auxiliar a pensar as principais mudanças que, potencialmente, interferem na prática publicitária, como o reconhecimento do campo publicitário e suas lógicas de produção, bem como da agência enquanto lugar da prática publicitária. Ainda, como um dos aspectos compreendidos como fundamentais da vida contemporânea, abordamos a noção de aceleração do tempo e sua interferência na prática da publicidade e propaganda como suporte para 0 entendimento das dimensões que atravessam o fazer publicitário.

A considerar essas dimensões, o principal objetivo da pesquisa reside em buscar identificar essas possíveis mudanças a partir de um modelo clássico do negócio da propaganda, reconhecendo o que começa a se transformar e que projeções futuras já existem. Fazemos isso a partir do mercado do Rio Grande do Sul, porque está inserido em nossa própria realidade de investigadores e porque nos facilita a aproximação face a face com nossos entrevistados no campo. Mas entendemos que é um movimento que reverbera de forma muito similar em todo o país.
Como etapa complementar da pesquisa, 0 presente artigo tem como finalidade contribuir para os aspectos centrais da investigação, avançando para uma dimensão que compreende ser essencial dentro deste processo de análise do modelo de negócios e do fazer publicitário: trata-se da fundação desse modelo, a considerar especialmente seu histórico e desenvolvimento. Assim, este texto tem como propósito recuperar algumas questões centrais que dimensionaram o negócio publicitário desde o seu surgimento até a atualidade. Parte-se do pressuposto que a publicidade de hoje - a considerar as novas tecnologias, a interação, as novas linguagens, 0 consumidor engajado, os públicos segmentados e a pulverização das mídias existentes - tem sofrido dificuldades em ajustar seu modelo de negócios a essa nova realidade, tendo em vista a sólida constituição deste mercado publicitário sedimentando financeiramente sobre o modelo das grandes mídias de massa.

\section{As agências e o fazer publicitário}

0 campo publicitário é constituído por diversos atores, entre eles, agências de propaganda, veículos de comunicação, gráficas, produtoras de áudio e vídeo, agências web e empresas de pesquisa de mercado. 0 principal negócio deste mercado é a propaganda, entendida aqui como

Trabalho apresentado no GT de História da Publicidade e da Comunicação Institucional, integrante do $10^{\circ}$ Encontro Nacional de História da Mídia, 2015. A pesquisa que deu origem ao presente artigo teve a contribuição da bolsista PIBIC/CNPq Rita de Cássia Breier Bombardelli.

A referida pesquisa contou com o auxílio da bolsista de Iniciação Científica PIBIC/CNPq Rita de Cássia Breier Bombardelli, na coleta de dados do campo e de levantamento bibliográfico. 
"qualquer forma remunerada de difusão de ideias, mercadorias ou serviços, por parte de um anunciante identificado" (Presidência da República. Lei n ${ }^{0}$ 4.680/65).

Inspirados em Charaudeau ${ }^{3}$ (2009), entendemos o campo publicitário suportado sobre as agências, aqui compreendidas como empresas que fabricam informação e que integram diversas lógicas, dentre as quais se destacam as de ordem econômica, tecnológica e simbólica. Esses são conceitos fundamentais para 0 entendimento de toda a discussão proposta neste artigo, uma vez que se compreende a relação entre estas lógicas como articuladoras de todo o processo e seus decorrentes resultados.

Assim, cabe destacar que a lógica econômica consiste no fazer viver uma empresa. Sob o ponto de vista do campo publicitário, o que regula a lógica econômica diz respeito ao movimento financeiro do mercado e aos investimentos realizados em mídia e publicidade. Já a lógica tecnológica se refere à qualidade e quantidade de difusão de seus produtos. É regulada a partir dos meios e da tecnologia disponíveis para que esta prática aconteça. Essa lógica afeta diretamente na questão do tempo e seu significado no campo publicitário, tendo em vista que os processos adquiriram mais agilidade tanto na produção quanto na veiculação e, especialmente, na interação entre os sujeitos produtores e receptores de mensagem. Para

Charaudeau (2009), ambas as lógicas, econômica e tecnológica, são consideradas incontornáveis, e estão interligadas.

Quanto à lógica simbólica, é aquela que trata "[...] da maneira pela qual os indivíduos regulam as trocas sociais, constroem as representações dos valores que subjazem a suas práticas, criando e manipulando signos e, por conseguinte, produzindo sentido" (Charaudeau, 2009, p. 16). Sob o ponto de vista da prática, acreditamos que esta lógica reflete diretamente no produto publicitário e é regulada pela cultura organizacional da agência. Ou seja, é 0 conjunto de símbolos e significados que circulam e constituem a sociedade, mas também que estruturam a agência enquanto organização e lugar do fazer publicitário.

A considerar esses aspectos, a questão que se coloca e se deseja desvendar é: se 0 consumidor, 0 mercado e 0 cliente mudaram e se a cultura social e simbólica se transformou - alterando práticas, hábitos e significados para os sujeitos -, o que, verdadeiramente, mudou nas agências e no modo de fazer publicidade?

Hoje, no Brasil, existe um grande mercado de agências de propaganda. Um negócio que movimentou, no ano de 2014, mais de $\mathrm{R} \$ 120$ 
bilhões (Ibope Media, 2015). Se considerarmos que a publicidade esteve, por longos anos, vinculada a um modelo sustentado na rentabilidade dos altos investimentos em mídia realizados por seus clientes, é inevitável pensar sobre a nova lógica que começa a se instalar no mercado publicitário. Esta lógica reúne todas as mudanças que interferem na prática publicitária e em seus modelos de negócio. Talvez a principal destas mudanças esteja centrada nas inúmeras transformações promovidas pela era digital: (1) sua interferência sobre os meios de comunicação com novos formatos e linguagens; (2) o novo perfil do consumidor, engajado neste processo socioinformativo e ancorado por uma cultura da interação/expectativa de participação; (3) 0 mundo do trabalho centrado na aceleração do tempo e suas implicações, como as entregas imediatas e a efemeridade da inovação (que a todo momento é colocada à prova, porque algo novo já surgiu). Assim, parece ser difícil inovar em modelos quando as movimentações são constantes.

Cabe, então, uma retomada sobre a propaganda e suas práticas, desde 0 seu surgimento, a fim de que seja possível compreender, no contexto atual, o lugar em que ela se encontra e suas projeções futuras.

\section{Corretagem de anúncios: 0 princípio}

Segundo diversos registros históricos, a prática da propaganda no Brasil tem início com a figura do corretor de anúncios. Os depoimentos dessa história são de variadas fontes, muitos deles de publicitários, professores da área, pesquisadores e até mesmo de associações e entidades.

Como a propaganda brasileira teve sua história ancorada no modelo norte-americano, damos início pelos relatos do processo no mercado dos Estados Unidos, aqui relatados por Rana Said (2002), publicitária, professora universitária e pesquisadora. Seus questionamentos sobre o setor da publicidade passam pelos mesmos interesses de nossa pesquisa, na medida em que entende que é impossível discutir a atualidade do ambiente de negócios publicitários sem examinar as raízes históricas do processo de remuneração das agências. Diz ela:

Em meados do século XIX, o ancestral do homem de publicidade era 0 indivíduo que trabalhava para os editores de jornais. Embora 0 seu papel fosse vender espaço para os anunciantes, na verdade ele não era um "atacadista de espaço", como sugerem alguns relatos. Trabalhando em nome dos editores de jornais, 0 agente de publicidade captava anúncios de diversos clientes em troca de uma comissão sobre o preço do espaço. 0 desenvolvimento histórico do sistema de comissões e da agência de publicidade evoluiu em quatro fases principais [...]. (Said, 2002, p. 122)

Para Said, as quatro principais fases consistem nas seguintes: (1) 0 agente direto do editor inaugurado em 1841, por Volney Palmer, que fazia as negociações e firmava os contratos entre veículos e clientes; aqui, as comissões eram pagas pelo veículo ao agente; (2) 0 agente como corretor - tem início em 1865, por George Rowell, que comprava os espaços em larga escala dos 
veículos e os revendia em unidades menores aos anunciantes; (3) a fase do contrato aberto - em 1875 , por N. Ayer, que abre aos anunciantes as verdadeiras taxas cobradas e se propõe a ser 0 comprador destes espaços pelo menor valor, mas cobrando uma taxa pelo seu serviço, equivalente a $15 \%$ do custo bruto do espaço; aqui, o pagamento passa a ser do anunciante diretamente ao agente; e (4) agente para agência - início do século XX, as agências expandem suas áreas de especialização e consultoria de criação e preparação de anúncios, e o papel do agente como comprador deixa de ser suficiente para justificar as comissões pagas; a American Newspaper Publishers' Association determina que a comissão deveria ser paga somente às agências e que não se concederia redução de preço equivalente aos anunciantes diretos.

Sob nosso ponto de vista, de todas estas fases, a primeira já indica uma característica que irá permear muitos dos negócios publicitários ainda nos dias de hoje: 0 valor do espaço publicitário antes do próprio conteúdo.

De acordo com Said (2002), Volney Palmer, descrito por muitos como o primeiro homem de publicidade, fundou o que seria uma agência de publicidade em 1841, na Filadélfia, com a finalidade de representar jornais que desejavam vender seus espaços comerciais.

Ele oferecia um local onde (a) 0 vendedor de espaço podia encontrar um comprador e, vice-versa, um comprador podia encontrar um vendedor e (b) o preço a pagar podia ser discutido entre ambas as partes. Palmer trabalhava especificamente para editores de jornais [...].(Said, 2002, p. 123)

Como explica Said (2002), em alguns casos, Palmer chegava a exigir que 0 editor 0 reconhecesse como seu único agente, firmando contratos em nome do comprador e do vendedor de espaço. Sua comissão costumava ser de $25 \%$ sobre o faturamento bruto do espaço, mas chegou a $40 \%$, tamanho valor que os editores conferiam ao volume de vendas realizado por Palmer. 0 sucesso de Palmer instigou a concorrência que, como efeito, gerou a diminuição das taxas de publicidade estipuladas nas tabelas de preço. "Foi somente nos últimos anos da década de 1960 que a concorrência entre os agentes começou a influenciar o nível das comissões, que então foi reduzido para um patamar-padrão de 15\%" (Said, 2002, p. 122).

No decorrer do período e com as mudanças de fase, nota-se que 0 importante até então são as taxas de negociação. "0 papel do agente estava longe de ser percebido como o de um consultor de estratégia e de criação" (Said, 2002, p. 125). No entanto, no início do século XX, quando qualquer agência começou a ter acesso às listas de jornais e às negociações de espaço, o papel do agente como comprador deixa de ser suficiente para justificar as comissões pagas pelos veículos. "Por conseguinte, as agências começaram a expandir suas áreas de especialização para incluir consultoria de criação, preparação de anúncios 
e outros serviços que são comuns hoje em dia"

(Said, 2002, p.125).

No Brasil, a história da publicidade segue um percurso muito similar, como verba de sustentação para viabilização do negócio da mídia. "Sim, no princípio era a verba. Desde 1808, no mês de setembro, com a instituição da Impressão Régia, o anúncio publicitário entrou na história da comunicação social do Brasil.[...]" (Chueiri, 1990, p.264). Ainda segundo Chueiri, 0 anúncio acontece neste primeiro momento através do anunciante. São pessoas físicas, com oferta de seus serviços, como costureiros, cabeleireiros, professores, entre outros, ou pessoas jurídicas com anúncios do comércio local ou produtos manufaturados.

Com a chegada de outros veículos, a disseminação aumenta, e anúncios e anunciantes começam a fazer parte do cotidiano do leitor. Como relata Chueiri,

Pagando a publicidade (ou a propaganda), segmentando públicos e mercados [...] 0 anunciante da época já apresentava, de forma pública, a vocação de disseminador de riquezas, socializando produtos e serviços, não se conformando apenas em ser um apresentador metropolitano de produtos em prateleiras e vitrines. Tampouco um prestador de serviços para os seus vizinhos de rua ou de bairro (Chueiri, 1990, p.265).

Com o desenvolvimento técnico e a

profissionalização dos veículos, os quais passam a se organizar de forma mais empresarial, surge a figura do "agenciador de anúncios", que viria a se tornar 0 assessor que 0 anunciante precisava.
Com isso, a função-meio da propaganda - sob o ponto de vista do anunciante - torna-se a funçãofim - na visão do agenciador (Chueiri, 1990).

No Brasil, segundo levantamentos realizados por Ramos (1987), não existiram, antes de 1913, escritórios com a função organizada em distribuir anúncios para os jornais. Pelos relatos históricos, a primeira firma que pode merecer classificação de agência de publicidade instalou-se em São Paulo, entre 1913 e 1914. Chamava-se Castaldi \& Bennaton, proprietária de A Eclética (Ramos, 1987).

Sobre A Eclética, Queiroz (2005) conta que, na visão de Julio Cosi Jr (sucessor de seu pai na nova fase da agência), os fundadores Castaldi e Benaton eram

[...] na verdade, contadores nas empresas em que trabalhavam. Como estas empresas começaram a precisar publicar seus balancetes e anúncios em jornais impressos, tiveram os dois, igualmente inspirados pelo modelo norte-americano de gestão empresarial de agências de publicidade, a ideia de fundar um negócio que tinha como objetivo a comercialização de anúncios (Queiroz, 2005, p.11).

A Eclética inicia-se como uma firma voltada para a venda de espaços de anúncios que evolui no sentido da publicidade e $\log _{0}$ se transforma em agência. Na sua transformação, modificase a estrutura da empresa, e a agência ganha importância. No princípio, foi a associação do jornalista João Castaldi ao homem de negócios Jocelyn Benaton. Em seguida, eles se associam a Eugênio Leuenroth, que até então havia 
atuado como gráfico e jornalista. Mais tarde, em 1918, Júlio Cosi entra para a sociedade, e Eugênio Leuenroth é transferido para a filial recém-inaugurada no Rio de Janeiro, onde acumularia também as funções de representante de O Estado de São Paulo (Ramos, 1987). Este acúmulo de função indicava que as dimensões veículo e agência ainda eram muito sobrepostas, muito possivelmente para a garantia da verba, necessária à sobrevivência do negócio.

No Rio Grande do Sul, a primeira configuração de um negócio nos moldes de agência foi a empresa Sociedade Técnica de Anúncios e Representações Limitada, mais conhecida por STAR. Seu início, em 1932, também esteve sustentado no modelo de venda de espaços comerciais de jornal. "A Star [...] era em ordem de grandeza de tarefas mais uma distribuidora do Diário Oficial da União do que a empresa de propaganda como hoje é reconhecida. No entanto, faça-se justiça, 'produziu' peças publicitárias que se destacavam nas páginas dos jornais" (Mafuz, 1990, p. 438).

Revisando os relatos históricos, observa-se que a força do modelo comercial da venda dos espaços é anterior ao fazer publicitário propriamente dito. E a publicidade se desenvolveu e evoluiu a partir desta dimensão. Neste modelo de interdependência, em que o meio precisa da publicidade e a publicidade precisa do meio, sedimentou-se uma prática pouco contestada. Pelo menos até então.

\section{Foco no conteúdo: o futuro?}

Atualmente, uma das grandes questões que se colocam sobre a prática publicitária é seu papel diante de tantas transformações sociais e culturais. Se estas mudanças impactaram com tanta força os sujeitos, seus hábitos e modos de consumo, é inevitável que se pense sobre esse chamado novo consumidor à frente dos processos.

Se hoje existe um debate sobre a relevância do conteúdo como o centro do pensamento estratégico do fazer publicitário, é porque 0 sujeito consumidor está sendo considerado como relevante e, mais do que isso, como decisor do processo comunicativo. Talvez o primeiro movimento que coloca 0 consumidor em um papel de relevância no processo de consumo, no Brasil, tenha sido o Código de Defesa do Consumidor, o qual entrou em vigor em março de 1991.

Sustentado pelas normas do código, o sujeito consumidor, ainda que timidamente, começa a ter 'vez' e 'voz'. Acima de tudo, a partir desta revisão de valores, 0 consumidor passa a compreender que, sem sua figura, o consumo não acontece.

Dos anos 1990 para os anos 2000, a transformação se acentua com o desenvolvimento da tecnologia e dos processos interativos, especialmente os potencializados pelas redes sociais. Esse desenvolvimento gera novas ferramentas e novas mídias, fato que dá início à pulverização da verba publicitária. E, talvez, a maior novidade percebida em todo processo seja 
o público consumidor, que assume seu lugar na interação, apoiando causas e comprando, muito mais do que produtos, ideias.

Acompanhar essas transformações não foi tão fácil. Para Marcondes (1995), as agências sempre tiveram dificuldade de encarar mudanças drásticas. E a entrada da tecnologia em seus espaços foi lenta. Quando, na década de 1980, os computadores já faziam parte do cotidiano de diversas empresas, em vários setores, as agências e seus gestores ainda relutavam:

Javier Ciuret, Diretor-Superintendente da então mais criativa agência do país, a DPZ, ironizava: "No dia em que os computadores fizerem criação, a DPZ vai ser a primeira a comprá-los".

Computadores viriam sim, apesar de Ciuret, a ser peça fundamental em sua agência. Inclusive e principalmente na sua criação. Assim, como na MPM, cujo Diretor de Mídia na época, Reinaldo Wilke, questionava os custos de implantação da informática na agência (justo um homem de mídia), achando-os excessivos. (Marcondes e Ramos, 1995, p.114-115)

De fato, como esclarece Marcondes (1995), os valores para investir neste campo eram mesmo assombrosos, mas a verdade é que os computadores demoraram a chegar nas agências, em tese, um setor em que eles deveriam ser compreendidos como fundamentais. "Como diria Paulo Salles, da Salles/Interamericana, 'não utilizar computador é temer o novo'." E reforça Marcondes, "as agências temeram o novo, até que o novo fosse inevitável" (Marcondes e Ramos, 1995, p.155).
0 investimento em tecnologia significaria também tudo o que dela poderia resultar. No princípio, como ferramenta de criação, finalização e agilização dos processos. Depois, viriam ainda outras dimensões, como a web e suas possibilidades, bem como todas as discussões sobre os novos modelos resultantes destes processos versus os modelos tradicionais de publicizar. Como relata Daniel Skowronsky no livro da Associação Riograndense da Propaganda (ARP, 2002), o qual recupera as memórias da propaganda gaúcha,

\section{[...] a história mostra que esta não é a primei- ra vez que uma nova plataforma de conteúdo questiona as certezas de uma época. Tanto 0 rádio quanto a televisão exigiram uma ginástica criativa dos publicitários. E o mercado se adap- tou. Algumas empresas se encaixam nas novas circunstâncias. Outras deixam de existir. A con- tinuidade do negócio de propaganda é possível porque profissionais de diferentes gerações convivem juntos, e os mais jovens absorvem os ensinamentos dos mais experientes, numa troca que gera - mais uma vez - novas ideias (ARP, 2002, p.11).}

Ainda assim, a web e seus resultados sobre os processos produtivos e criativos se configuraram talvez como a principal transformação da atualidade. Na publicidade, ela vai chegar entre o fim dos anos 1990 e o começo dos anos 2000, ainda sofrendo todas suas limitações: "Nesses anos, a 56kbps, com conexão discada, a internet começava a entrar no dia a dia das recentemente informatizadas empresas de publicidade do Rio Grande do Sul, conectando computadores que ainda aceitavam disquetes" (ARP, 2002, p.118). 
Com esses limitadores, o uso ainda era muito restrito, assim como era compreender o papel que ela poderia assumir.

Tão complexo quanto imaginar um mundo sem redes sociais, sem download de vídeos, Google ou Twitter, era o mercado entender naquela época 0 outro lado da internet, além das facilidades que ela prometia para 0 trabalho: 0 que fazer com isso enquanto ferramenta de comunicação para os meus clientes? (ARP, 2002, p.118)

Nesse ambiente, surgiram as primeiras agências digitais do Rio Grande do Sul, entre elas AG2 e W3haus. Algumas agências optaram também em criar núcleos web que dessem conta desse novo pensamento dentro da prática publicitária. Mas, como toda novidade, o processo foi sendo descoberto aos poucos e sendo testado como uma novidade que ainda não se sabia ao certo onde iria chegar.

0 certo é que nos primeiros cinco anos do novo século, nessa era pré-YouTube, pré-redes sociais, ou como dizem os que atuam na área, antes da internet 2.0 (a internet colaborativa), dentro das agências, talvez a internet tenha tido um pouco mais de interesse nos departamentos de criação, que enxergavam novas possibilidades de criar, novos formatos para explorar (ARP, 2002, p.120).

Ainda conforme os depoimentos da ARP (2002), os donos das empresas publicitárias não deram muita atenção à comunicação digital. Prova disso foram os investimentos tímidos e reativos em geral dos núcleos digitais pouco estruturados, quase sempre a partir da colaboração de estagiários ou profissionais juniores.
Por não perceberem ainda o poder da ferramenta, a explosão da bolha internet [...] ou por não observarem uma forma atrativa e compreensível de remuneração neste universo, os homens que tocavam o negócio, e por consequência suas agências, fizeram pequenos avanços e um longo retrocesso ou uma pausa nas investidas no mundo virtual (ARP, 2002, p.120).

Ao mesmo tempo, as agências tradicionais notam que as agências digitais que começam a crescer em tamanho e faturamento - ao contrário do que as tradicionais estavam habituadas - não se configuram no mesmo modelo de produtoras de áudio e vídeo, ou seja, de prestadoras de serviço apenas, fornecendo tecnologias, banners e websites. Mais do que isso, elas começam a se consolidar como estruturas de pensamento estratégico de comunicação digital, que compreendem o processo interativo oferecido pelo ambiente e pela cultura digital e seu consequente impacto na relação entre 0 mundo das marcas e 0 universo do consumidor.

E as marcas se integram rapidamente a esse processo. Como apontam os relatos levantados pela ARP (2002, p.120), inúmeros anunciantes mundiais começaram a direcionar parte da verba de TV para a internet, e grupos reconhecidos de publicidade optaram por fazer grandes investimentos na compra de empresas de criação e comunicação digital.

[...] 0 que já era difícil de explicar no começo dos anos 2000, a partir do meio da década ficou ainda mais confuso. A única certeza era de que, agora, os donos das 
agências não poderiam mais evitar 0 assunto nas reuniões com os clientes. [...] Com as mudanças ocorrendo não mais a 56bkps, mas na velocidade dos megabytes e em crescente aceleração, a sensação generalizada era de que não havia tempo para pensar, e a impressão é de que 0 método tentativa e erro (e alguns acertos) consagrava-se como a única saída possível. (ARP, 2002, p.120)

De acordo com a publicação da ARP, para alguns publicitários existe a impressão de que o mercado tem agido de uma forma um pouco reacionária à imposição da internet no modelo das agências publicitárias. Talvez esse comportamento se deva ao fato ressaltado por alguns donos de agências de que, "se o mundo digital mexe com a criatividade e abre novas possibilidades, aguçando 0 apetite de criativos e anunciantes por novidades, também traz desordem no formato de remuneração das agências" (ARP, 2012, p.124).

Talvez esteja aí um dos grandes pilares, difíceis de mover na estrutura do modelo de negócio publicitário, que diz respeito a um formato de remuneração já consagrado e que funcionou por muito tempo. Mover-se desse processo é custoso e delicado. Implica em novas abordagens e práticas advindas tanto das agências quanto das empresas anunciantes.

Acerca desse aspecto, a ARP cita o publicitário Márcio Callage, vice-presidente da DM9Sul, que traz uma posição muito próxima ao que este artigo pretende provocar a pensar:
[...] a organização encontrada na maioria das agências atuais é um desenho que surgiu na década de 1950 e que passou por mudanças mínimas ao longo de 60 anos. E faz parte desse modelo o meio como as empresas aprenderam a se remunerar: com porcentagens sobre a veiculação e a produção de formatos fixos de publicidade como os comerciais de 30 segundos ou os anúncios de página inteira em jornais e revistas. (ARP, 2012, p.124).

Hoje, este modelo está em debate porque não compreende apenas pensar nas mídias como estrutura basilar de uma campanha. A própria ARP, que representa os publicitários gaúchos, se posiciona a esse respeito lembrando que, se, no início, a revolução da internet era basicamente tecnológica, com o tempo ela passou a ser também social. "Em meio a tantas discussões sobre inovações, mudanças, transformações [...] existem casos no mercado gaúcho de uma transição ou assimilação quase pacífica deste momento, para tantos, conturbado" (ARP, 2012, p.121). Um exemplo é o da rede rio-grandense de supermercados Zaffari:

Em vez de produtos, a rede estampou o conceito da marca nos comerciais. Ao oferecer a experiência prazerosa de compra e fortalecer a relação com a comunidade, a empresa criou condições para que o público criasse uma relação amistosa com a marca. Eram os primórdios da viralização, isto é, a disseminação espontânea de conteúdo - e de marcas - que passou a se tornar uma meta para os criativos. (ARP, 2012, p.121)

Neste caso, a dimensão que se evidencia é de explorar emoções, apelar para a experiência de compra e investir em relacionamentos. 0 conteúdo 
como provocador de todas estas dimensões ganha valor de mercado e estrutura os novos pensamentos estratégicos em publicidade.

Em entrevista publicada na revista Meio \& Mensagem (abril, 2015), o CEO da rede Ogilvy, Miles Young, deixa claro o valor do conteúdo, colocando-0 acima das campanhas. Segundo ele, a agência Ogilvy já vem trabalhando com essa perspectiva. De acordo com essa linha, Young entende que as agências passarão a funcionar como publishers, tendo o conteúdo como base de todo o processo. Em suas palavras:

Antes, a palavra agência significava que éramos agentes dos veículos. Agora, as agências adotarão um ponto de vista diferente sobre a comunicação e serão como os publishers. As agências vão operar de forma parecida à de uma redação e os publicitários começarão a atuar como editores. [...] No final das contas, as agências vão editar conteúdos e entregá-los (Meio \& Mensagem, 2015)

Os formatos que já começam a se reestruturar sinalizam uma nova perspectiva sobre a área. Acredita-se que os modelos até então sedimentados passarão por transformações inevitáveis. Pode demorar mais tempo do que imaginamos, mas a mudança que parecia tão distante dá indícios de que já começou.

\section{Considerações finais}

Após esta revisão histórica e análise da atualidade, cabe levantar aqui dimensões que se entendem relevantes, para seguir pensando sobre a prática publicitária e seus modelos de negócio. Sabe-se que, acerca de um processo que se mostra estruturado há tanto tempo no fazer publicitário, não se imaginam transformações revolucionárias em tão pouco tempo. No entanto, ao observar as transformações ocorridas no mercado da publicidade, é possível identificar indícios representativos e interessantes e que começam a dar sinais de impacto nos modelos do negócio publicitário.

0 primeiro deles é a revisão sobre a verba da mídia como principal fonte das agências. Mesmo que nos tempos atuais este modelo ainda represente a maior rentabilidade das grandes estruturas de agências brasileiras, o modelo está em pleno debate, gerando crises profissionais e, por que não dizer, éticas, na medida em que o publicitário reconhece a existência de alternativas mais eficientes a um custo mais acessível.

0 segundo aspecto também não é completamente novo, mas está a cada dia mais tomando o debate das agências: trata-se do valor do conteúdo e de como os novos profissionais deverão estar preparados para administrar essa dimensão com qualificação, conhecimento e capacidade. A capacitação em redação qualificada e não somente criativa na publicidade é um caminho a ser considerado, especialmente na formação acadêmica e profissional da área.

É inevitável, a considerar as lógicas propostas por Charaudeau (2009) e nas quais sustentamos nosso olhar sobre a prática da publicidade e seu 
negócio, que se organize esse modelo a partir destes três lugares: a lógica econômica, a lógica tecnológica e a lógica simbólica. A primeira sobrepõe-se às demais por uma condição inata da própria natureza do negócio. 0 lucro é a atividadefim da publicidade, bem como para as instâncias às quais ela serve, sejam as mídias ou as marcas. No entanto, percebe-se que as lógicas tecnológica e simbólica começam a intervir com força naquilo que pode representar um novo modo de estrutura das agências e de seus modelos e práticas.

É necessário que se pense nesse processo com olhar aguçado, curioso e sem esperar a próxima novidade. Sabe-se que, em breve, novas ferramentas surgirão, novos formatos irão nos desacomodar outra vez, e o repensar a prática seguirá sendo nosso maior desafio. Mas talvez, junto deste desafio contínuo que implica atualizar o fazer publicitário, tenhamos a missão de desenhar um novo modo de perceber seu papel como empreendimento e como gerador de ideias com valor substancial.

\section{Referências}

ARP - ASSOCIAÇÃO RIOGRANDENSE DE

PROPAGANDA. Ideias Registradas: 0 livro que conta as histórias da propaganda gaúcha. Porto Alegre: Pluralcom, 2012.

CHARAUDEAU, Patrick. Discurso das mídias. São Paulo: Contexto, 2009.

CHUEIRI, Carlos Roberto. E, no princípio, era a verba... In: CASTELO BRANCO, Renato, MARTENSEN, Rodolfo Lima, REIS, Fernando (coord.). História da propaganda no Brasil. São Paulo: T.A.Queiroz, Editor, 1990, p. 264-277.

IBOPE MEDIA. Investimentos Publicitários de 2014. Disponível em: < http://www.ibopemedia.com/ investimentos-publicitario-de-2014/> . Acesso em: 5 mai. 2015.

MAFUZ, Antonio. Rio Grande do Sul: a pequena Star foi a pioneira. In: CASTELO BRANC0, Renato, MARTENSEN, Rodolfo Lima, REIS, Fernando (coord.). História da propaganda no Brasil. São Paulo: T.A.Queiroz, Editor, 1990, p. 438-446.

MARCONDES, Pyr e RAMOS, Ricardo. 200 anos de propaganda no Brasil: do reclame ao cyber-anúncio. São Paulo: Meio \& Mensagem, 1995.

MEIO \& MENSAGEM. Agências vão virar publishers. Disponível em < http://www.meioemensagem.com.br/ home/comunicacao/noticias/2015/04/06/Ag-ncias-v-0virar-publishers.html > . Acesso em: 6 abr. 2015.

PRESIDÊNCIA DA REPÚBLICA. Casa Civil. Subchefia para Assuntos Jurídicos. Lei 4.680/65. 18/jun/1965. Disponível em: < http://www.planalto.gov.br/ccivil_03/ leis/4680.htm > . Acesso em: 9 jul. 2014.

QUEIR0Z, Adolpho (org). Propaganda, história e modernidade. Piracicaba: Editora Degaspari, 2005.

QUEIROZ, Adolpho. A propaganda no Brasil, da tradição oral ao mundo virtual. In: QUEIROZ, Adolpho (org). Propaganda, história e modernidade. Piracicaba: Editora Degaspari, 2005, p. 7-19.

RAMOS, Ricardo. Do reclame à comunicação: pequena história da propaganda no Brasil. $4^{\mathrm{a}}$ ed. São Paulo: Atual Editora, 1987.

SAID, Rana S. Os sistemas de remuneração das agências de publicidade. In: JONES, John Philip (org.). A publicidade como negócio. São Paulo: Nobel, 2002, p. 122-132. 


\section{From media's strength to content's power: revision of business models in advertising}

\section{Abstract}

Part of a wider research, this article rises data that allows identifying changes in the advertising practice, enhanced by social, cultural and technological changes. It intends to review the evolution of the models of advertising agencies in Brazil, identifying the advertising field and its changes over the years. The final research wants to recognize: how these changes impact in the advertising market? It is an exploratory approach, with bibliographical and documentary researches. As a result, it is noticed - without disregarding the natural economic logic of the advertising business - the technological and symbolic logics start to intervene with strength in advertising practice.

\section{Keywords}

Advertising. Remuneration by media. Power content.

\section{De la fuerza de los medios al poder} del contenido: revisión de modelos de negocio en la publicidad

\section{Resumen}

A partir de una investigación más amplia, el artículo evidencia datos que permiten identificar qué cambios ocurren en la práctica publicitaria, potencializados por las transformaciones sociales, culturales y tecnológicas. Traza la evolución de los modelos de agencias de publicidad en Brasil, asumiendo el campo publicitario y sus cambios a lo largo de los años. La investigación final pretende reconocer cómo esos cambios impactan en el mercado publicitario. Se trata de una investigación exploratoria, con revisión bibliográfica y documental. Como resultado, se ve que, sin dejar de considerar la lógica económica natural del negocio publicitario, las lógicas tecnológica y simbólica comienzan a intervenir con fuerza en el modo de pensar y de hacer publicidad.

\section{Palabras clave}

Publicidad. Remuneración a través de los medios. Poder del contenido. 


\section{Expediente}

A revista E-Compós é a publicação científica em formato eletrônico da Associação Nacional dos Programas de Pós-Graduação em Comunicação (Compós). Lançada em 2004, tem como principal finalidade difundir a produção acadêmica de pesquisadores da área de Comunicação, inseridos em instituições do Brasil e do exterior.

\section{E-COMPÓS I www.e-compos.org.br I E-ISSN 1808-2599}

Revista da Associação Nacional dos Programas de Pós-Graduação em Comunicação.

Brasília, v.18, n.3, set./dez. 2015.

A identificação das edições, a partir de 2008, passa a ser volume anual com três números.

Indexada por Latindex I www.latindex.unam.mx

\section{CONSELHO EDITORIAL}

Alexandre Farbiarz, Universidade Federal Fluminense, Brasil Alexandre Rocha da Silva, Universidade Federal do Rio Grande do Sul, Brasil Ana Carolina Damboriarena Escosteguy, Pontifícia Universidade Católica do Rio Grande do Sul, Brasil

Ana Carolina Rocha Pessôa Temer, Universidade Federal de Goiás, Brasil Ana Regina Barros Rego Leal, Universidade Federal do Piauí, Brasil Andrea França, Pontifícia Universidade Católica do Rio de Janeiro, Brasil André Luiz Martins Lemos, Universidade Federal da Bahia, Brasil Antonio Carlos Hohlfeldt, Pontifícia Universidade Católica do Rio Grande do Sul, Brasil

Arthur Ituassu, Pontifícia Universidade Católica do Rio de Janeiro, Brasil Álvaro Larangeira, Universidade Tuiuti do Paraná, Brasil Ângela Freire Prysthon, Universidade Federal de Pernambuco, Brasil César Geraldo Guimarães, Universidade Federal de Minas Gerais, Brasil Cláudio Novaes Pinto Coelho, Faculdade Cásper Líbero, Brasil Daisi Irmgard Vogel, Universidade Federal de Santa Catarina, Brasil Denize Correa Araujo, Universidade Tuiuti do Paraná, Brasil Eduardo Antonio de Jesus, Pontifícia Universidade Católica de Minas Gerais, Brasil

Daniela Zanetti, Universidade Federal do Espirito Santo, Brasil Eduardo Vicente, Universidade de São Paulo, Brasil Elizabeth Moraes Gonçalves, Universidade Metodista de São Paulo, Brasil Erick Felinto de Oliveira, Universidade do Estado do Rio de Janeiro, Brasil Francisco Elinaldo Teixeira, Universidade Estadual de Campinas, Brasil Francisco Paulo Jamil Almeida Marques, Universidade Federal do Paraná, Brasil

Gabriela Reinaldo, Universidade Federal do Ceará, Brasil Goiamérico Felício Carneiro Santos, Universidade Federal de Goiás, Brasil Gustavo Daudt Fischer, Universidade do Vale do Rio dos Sinos, Brasil Herom Vargas, Universidade Municipal de São Caetano do Sul, Brasil Itania Maria Mota Gomes, Universidade Federal da Bahia, Brasil
Janice Caiafa, Universidade Federal do Rio de Janeiro, Brasil Jiani Adriana Bonin, Universidade do Vale do Rio dos Sinos, Brasil José Afonso da Silva Junior, Universidade Federal de Pernambuco, Brasil José Luiz Aidar Prado, Pontifícia Universidade Católica de São Paulo, Brasil Juçara Gorski Brittes, Universidade Federal de Ouro Preto, Brasil Kati Caetano, Universidade Tuiuti do Paraná, Brasil

Lilian Cristina Monteiro França, Universidade Federal de Sergipe, Brasil Liziane Soares Guazina, Universidade de Brasília, Brasil Luíza Mônica Assis da Silva, Universidade de Caxias do Sul, Brasil Luciana Miranda Costa, Universidade Federal do Pará, Brasil Malena Segura Contrera, Universidade Paulista, Brasil Maria Ogécia Drigo, Universidade de Sorocaba, Brasil Maria Ataide Malcher, Universidade Federal do Pará, Brasil Marcia Tondato, Escola Superior de Propaganda e Marketing, Brasil Marcel Vieira Barreto Silva, Universidade Federal da Paraíba, Brasil Maria Clotilde Perez Rodrigues, Universidade de São Paulo, Brasil Maria das Graças Pinto Coelho, Universidade Federal do Rio Grande do Norte, Brasil

Mauricio Ribeiro da Silva, Universidade Paulista, Brasil

Mauro de Souza Ventura, Universidade Estadual Paulista, Brasil Márcio Souza Gonçalves, Universidade do Estado do Rio de Janeiro, Brasil Micael Maiolino Herschmann, Universidade Federal do Rio de Janeiro, Brasil Mirna Feitoza Pereira, Universidade Federal do Amazonas, Brasil Nísia Martins Rosario, Universidade Federal do Rio Grande do Sul, Brasil Potiguara Mendes Silveira Jr, Universidade Federal de Juiz de Fora, Brasil Regiane Regina Ribeiro, Universidade Federal do Paraná, Brasil Rogério Ferraraz, Universidade Anhembi Morumbi, Brasil Rose Melo Rocha, Escola Superior de Propaganda e Marketing, Brasil Rozinaldo Antonio Miani, Universidade Estadual de Londrina, Brasil Sérgio Luiz Gadini, Universidade Estadual de Ponta Grossa, Brasil Simone Maria Andrade Pereira de Sá, Universidade Federal Fluminense, Brasil Veneza Mayora Ronsini, Universidade Federal de Santa Maria, Brasil Walmir Albuquerque Barbosa, Universidade Federal do Amazonas, Brasil

\section{COMISSÃO EDITORIAL}

Cristiane Freitas Gutfreind

Pontifícia Universidade Católica do Rio Grande do Sul, Brasil

Irene Machado

Universidade de São Paulo, Brasil

\section{CONSULTORES AD HOC}

Claudia Peixoto de Moura, Pontificia Universidade Católica do Rio Grande do Sul, Brasil Francisco Rüdiger, Pontifícia Universidade Católica do Rio Grande do Sul, Brasil Juremir Machado da Silva, Pontifícia Universidade Católica do Rio Grande do Sul, Brasil Maria Aparecida Baccega, Universidade de São Paulo, Brasil

Roberto Tietzmann, Pontifícia Universidade Católica do Rio Grande do Sul, Brasil

\section{EQUIPE TÉCNICA}

ASSISTENTE EDITORIAL I Márcio Zanetti Negrini

REVISÃO DE TEXTOS I Press Revisão

EDITORAÇÃO ELETRÔNICA I Roka Estúdio

CONTATO I revistaecompos@gmail.com
COMPÓS I www.compos.org.br

Associação Nacional dos Programas de Pós-Graduação em Comunicação

Presidente

Edson Fernando Dalmonte

Programa de Pós-Graduação em Comunicação

e Cultura Contemporânea - UFBA

edsondalmonte@uol.com.br

Vice-presidente

Cristiane Freitas Gutfreind

Programa de Pós-Graduação em Comunicação Social - PUC-RS cristianefreitas@pucrs.br

Secretário-Geral

Rogério Ferraraz

Programa de Pós-Graduação em Comunicação

Universidade Anhembi Morumbi

rogerioferraraz@anhembimorumbi.edu.br 